Research Article

\title{
Computational Model of Outer Circle and Inner Ellipse Shield Tunnel Lining Structure
}

\author{
Shuancheng Gu, ${ }^{1}$ Guanlin Sun ${ }^{1},{ }^{1}$ and Peili Su ${ }^{1,2}$ \\ ${ }^{1}$ School of Architecture and Civil Engineering, Xi'an University of Science and Technology, Xi'an, Shaanxi 710054, China \\ ${ }^{2} X i$ 'an Key Laboratory of Geotechnical and Underground Engineering, Xi'an University of Science and Technology, Xi'an, \\ Shaanxi 710054, China
}

Correspondence should be addressed to Guanlin Sun; sunguanlin067@163.com

Received 20 May 2021; Accepted 10 August 2021; Published 18 August 2021

Academic Editor: Camelia Delcea

Copyright (c) 2021 Shuancheng Gu et al. This is an open access article distributed under the Creative Commons Attribution License, which permits unrestricted use, distribution, and reproduction in any medium, provided the original work is properly cited.

\begin{abstract}
Subway tunnels are mostly located in strata with an uneven pressure. This uneven pressure is usually manifested by lateral pressure coefficients less than 1. To adapt to the unevenness of the stratum load, in this study, we propose a new shield tunnel lining structure-outer circle and inner ellipse shield tunnel lining structure-whose outer contour remains circular and the inner contour shape of the structure is designed according to the load conditions. We used the stiffness step discounting method to obtain the calculation coefficients used in the force method formulas and established the calculation model of the outer circle and inner ellipse shield tunnel linings. The force method was then used to determine the force distribution characteristics of the outer circle and inner ellipse shield tunnel lining structure. During the verification, it was sufficient to analyze whether the waist structure rigidity met the safety conditions. This simplifies the design elements. The internal space area of our proposed design is expanded by $0.86 \mathrm{~m}^{2}$ compared to the internal space area of the equal stiffness shield tunnel lining design.
\end{abstract}

\section{Introduction}

Shield tunnel linings have been widely used in urban subway tunnel construction. The thickness and shape of the linings are two important design factors influencing not only the safety of the tunnel but also have a considerable impact on the project cost. For this reason, many scholars have conducted research on this subject.

Several scholars have analyzed the mechanical properties of shield tunnel linings by theoretical derivation. Yan et al. [1] discussed in detail the relationship between the shield tunnel lining thickness and the maximum water pressure in a section of the Yangtze River tunnel in Wuhan. Chen et al. $[2,3]$, studied an acceptable shield tunnel lining thickness for a large-diameter highway tunnel located in the plateau region. They found that a change in the thickness of the shield tunnel lining has a small effect on the axial force of the shield tunnel lining structure and that an increase in the lining thickness results in an increase in the bending moment of the shield tunnel lining structure. Ding et al. [4] explained that, as the thickness of the shield tunnel linings decreases, the bending moment also decreases and the axial force increases slightly. They also emphasized that project costs can be reduced by reducing the lining thickness appropriately provided that the strength and distribution of reinforcement requirements are met. Zhao and $\mathrm{He}$ [5] showed that the method of "thinning" shield tunnel linings with staggered seam assemblies is equivalent to the method of establishing bending requirements for thicker shield tunnel linings, while the deformation produced is small. Huang et al. [6] studied the effect of shield tunnel lining thickness on structural forces using model tests. Their results showed that, with an increase in the shield tunnel lining thickness, the change in the internal forces of the structure is greatest in the arch waist and less in the arch top and arch bottom in that order. Furthermore, they found that an excessive shield tunnel lining thickness is not beneficial to the structural forces of the tunnel. Huang et al. $[7,8]$ found that, with an increase in the shield tunnel lining thickness, the bending moment gradually increases and the axial force 
gradually decreases. The change in the bending moment value is the most significant, and a larger shield tunnel lining thickness will result in a larger bending internal force and a reduction in the structural deformation capacity. Furthermore, they also concluded that additional lining thickness may not benefit the structure itself and will only cause a waste of the material.

Several scholars have used experimental methods to analyze the mechanical properties of shield tunnel linings. Yang [9] used numerical simulation to analyze the internal force deformation of shield tunnel linings under multiple working conditions and then determined the appropriate lining thickness for the various working conditions. Huang et al. [10] conducted a full-scale loading test of rectangular shield tunnel linings to reveal the mechanical behavior of the shield under the influence of its weight. Liu et al. [11, 12] conducted a full-scale annular test of rectangular shield tunnel linings to determine its mechanical properties and reveal its weak points and defined the safety coefficients in the elastic and ultimate stages, respectively. Zhu et al. [13] obtained the structural mechanical response and ultimate damage characteristics of rectangular shield tunnel linings under different load states through prototype tests and evaluated the rationality and reliability of its structural design. Ji [14] studied the building limits and structural mechanical characteristics of rectangular shield tunnel linings and proposed rectangular variable section shield tunnel linings. Guo et al. [15] used the geometric equations of circular arcs and the linear equations of intersecting straight lines to determine the circular arc parameters according to the characteristics of the outer contour of the tunnel lining and proposed a design method for a variable-section lining based on analytical geometry to determine the parameters of the outer contour of the structure.

Ding et al. [16], based on different characteristics of sealing gaskets used in segmental joints, subsequently conducted tests to evaluate the functionality of the test setup. The results demonstrated that local concrete damages around the groove flank could serve as a water leakage channel and reduced the sealant performance of gasket. Gong et al. [17] proposed a sealant mechanism based on the finite element analysis. A conceptual model is first established to identify sealant behavior of gasketed joint subjected to lateral water pressurization. A nonlinear finite element model is developed to simulate the gasket-in-groove sealant behavior, and the performance of the model is validated with experimental data. Gong et al. [18] conducted full-scale tests to study the ultimate bearing capacity of the conventional reinforced concrete (RC) and the SFRC joints under different loading conditions with a special attention on the corresponding cracking process. The experimental results demonstrated that the peak load bearing capacity of the SFRC joints was slightly higher than that of the RC joints. Andreotti et al. [19] proposed a cyclic model for longitudinal joints that is capable of simulating the cyclic behavior of asymmetric, bolted cross-sections. The distinctive feature of the proposed model is the variation of the rotational stiffness of the joint that depends on (i) the sign of bending moment, (ii) level of axial load, and (iii) damage accumulation or failure. The reliability of the formulation is evaluated through comparison with experimental data.

Katebi et al. [20] studied the effects of ground stratification, surface buildings specifications, and tunnel depth on lining loads. Lyu et al. [21] proposed a novel analytical approach to calculate tunnel pressure due to the surrounding rock of a twin-tunnel in layered strata. Wu et al. [22] proposed a new longitudinal structural model to consider the shearing dislocation between rings. Wang et al. [23] studied the effects of segmental joints, dimensions of segments, and ground conditions on buckling of the shield tunnel linings under hydrostatic pressure by analytical and numerical analysis.

In the above studies, it was assumed that the shape of the shield tunnel linings is kept constant in a circular shape, and the effect of thickness variation on the internal force of the shield tunnel linings was investigated. In addition, starting from the structural shape, the shield tunnel linings were designed as rectangles to expand the internal usable space and to analyze its mechanical properties and stability. However, there are still shortcomings in the results of numerous studies: (1) scholars have studied in-depth the effect of reducing the thickness of the shield tunnel linings on the structure, but the object of their study was still a structure of equal stiffness with uniform thickness, and the effect of ground load was not taken into account; (2) some scholars conducted studies on variable-section lining structures, but there are few published studies on this aspect, and there is a lack of relevant theoretical studies. Therefore, in this study, when the lateral pressure coefficient is less than 1, we propose an outer circular inner elliptical shield tunnel lining with a circular outer profile. We will study its computational model and analyze the internal force characteristics and stability evaluation. All the above results were compared with those of the equal-rigidity shield tunnel linings when the loading conditions are same to draw relevant conclusions.

\section{Calculation Model of Outer Circle and Internal Ellipse Shield Tunnel Linings}

2.1. Outer Circle and Internal Ellipse Shield Tunnel Linings. Shallow buried underground structures, such as urban subway tunnels, are often under uneven stratigraphic loads where the top pressure is greater than the lateral pressure. Therefore, it would be reasonable to determine the most economical structural form for the tunnel according to the actual stratigraphic pressure. However, considering the fabrication and construction environment, the round equalthickness shield tunnel linings are still the design most widely used, but mechanically, the circular structure can only benefit from its structural characteristics when it is subjected to uniform radial pressure. The elliptically shaped structure of the shield tunnel linings can adapt to the uneven stratigraphic load, but the outer profile of this design will make the shield construction more difficult. The rectangular design for the shield tunnel linings is conducive to the full use of the structure, but mechanically the straight structure design does not help the structural bending resistance. 
Equal-thickness shield tunnel linings are designed to meet the safety requirements of the most unfavorable location and then to apply the thickness calculated for the most unfavorable location to the full ring; therefore, although the design is convenient and the structural stiffness is large, the equal-thickness practice will inevitably cause material waste under uneven ground pressure, and the larger thickness of the shield tunnel linings is not beneficial to the stress of the structure itself.

Considering the unevenness of the ground load and referring to the structural form of shaped shield tunnel linings [24-28], while taking into account the factors of fabrication and construction, this study proposes a variable stiffness shield tunnel lining structure, which can be achieved in two ways: one, keeping the outer contour of the structure circular and adjusting the shape of the inner contour of the structure according to the load conditions, that is, adjusting the stiffness of the shield tunnel lining structure with the load distribution; second, keeping the thickness of the whole shield tunnel linings unchanged and adjusting the concrete strength or reinforcement rate appropriately. In other words, the variable stiffness shield tunnel lining structure ensures that the structural stiffness at the most unfavorable location meets the safety requirements and then appropriately reduces the structural stiffness at other locations so that the structure can achieve the purpose of adapting to the ground pressure, giving full play to the material characteristics, improving the utilization of internal space, and facilitating construction while reducing costs. Figure 1 shows a schematic diagram of the structure section of the outer circular inner elliptical shield tunnel linings, where $R$ is the radius of the circular outer profile of the shield tunnel linings. $r(\theta)$ is the radius of the inner profile of the shield tunnel linings, whose functional expression is determined by the specific shape.

\subsection{Calculation Model of Outer Circular and Internal Ellip-} tical Shield Tunnel Linings. The referenced literature [29] compared the calculation results of the inertial design, the multihinged circular, and the beam-and-spring model methods with actual results from engineering examples. Their results showed that the numerical solution of the

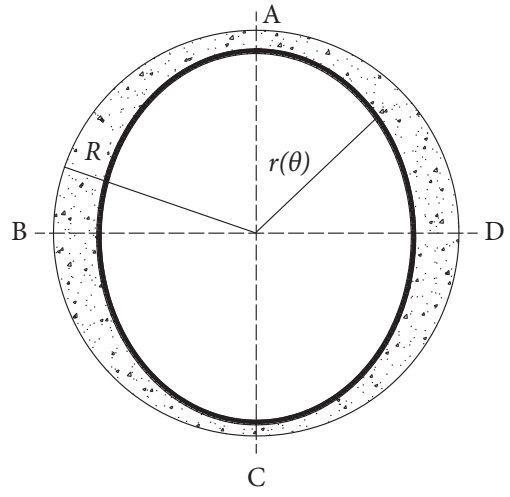

FIGURE 1: Schematic diagram of outer circle and inner ellipse shield tunnel linings.

inertial design method was closer to the engineering reality. Therefore, in this study, we use the load model of the inertial design method as the load model of the calculation model of the outer circular and inner elliptic shield tunnel linings. The basic structure and load modeling of the outer circular inner elliptic shield tunnel linings are shown in Figure 2, where the radius of the outer profile is $R$, inner profile radius is $r(\theta)$, width is $b l$, and the thickness of the top and bottom of the shield tunnel linings are $h_{A}$ and $h_{C}$, respectively. The thickness of the waist is $h_{B}$.

\subsubsection{Calculation Coefficients of Force Method for Outer} Circular and Internal Elliptical Shield Tunnel Linings. The cross-sectional moment of inertia and axial radius $r_{c}$ of the outer circular and inner elliptical shield tunnel linings are

$$
\begin{aligned}
I(\theta) & =\frac{b^{\prime} \cdot h(\theta)^{3}}{12}=\frac{b^{\prime}}{12}[R-r(\theta)]^{3}, \\
r_{c} & =\frac{R+r(\theta)}{2} .
\end{aligned}
$$

Bringing the above parameters into the calculation formula,

$$
\begin{aligned}
\Delta_{k P} & =\int_{s} \frac{M_{P} \bar{M}_{k}}{E I} \mathrm{~d} s+\int_{s} \frac{N_{P} \bar{N}_{k}}{E A} \mathrm{~d} s \\
& =\int_{0}^{\theta} \frac{M_{P} \bar{M}_{k}}{(E b / / 12)[R-r(\theta)]^{3}} \cdot \frac{R+r(\theta)}{2} \mathrm{~d} \theta+\int_{0}^{\theta} \frac{N_{P} \bar{N}_{k}}{E b /[R-r(\theta)]} \cdot \frac{R+r(\theta)}{2} \mathrm{~d} \theta .
\end{aligned}
$$

Because the stiffness of the outer circular inner elliptic shield tunnel lining structure is not a fixed value, the direct application of equation (2) will lead to a very complicated calculation process. Therefore, the step-folding algorithm [30-32] is used to step its inner contour and introduce the Heaviside function to describe the abrupt change phenomenon at the step, as shown in Figure 3, after which the flexibility coefficient and the free term are derived using the divisional integration method.

In the polar coordinate system, the Heaviside function can be defined as 


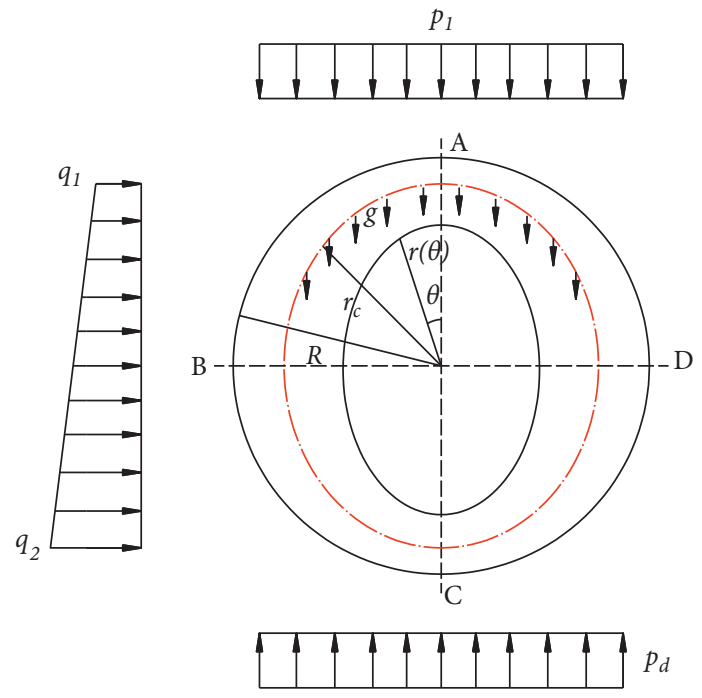

(a)

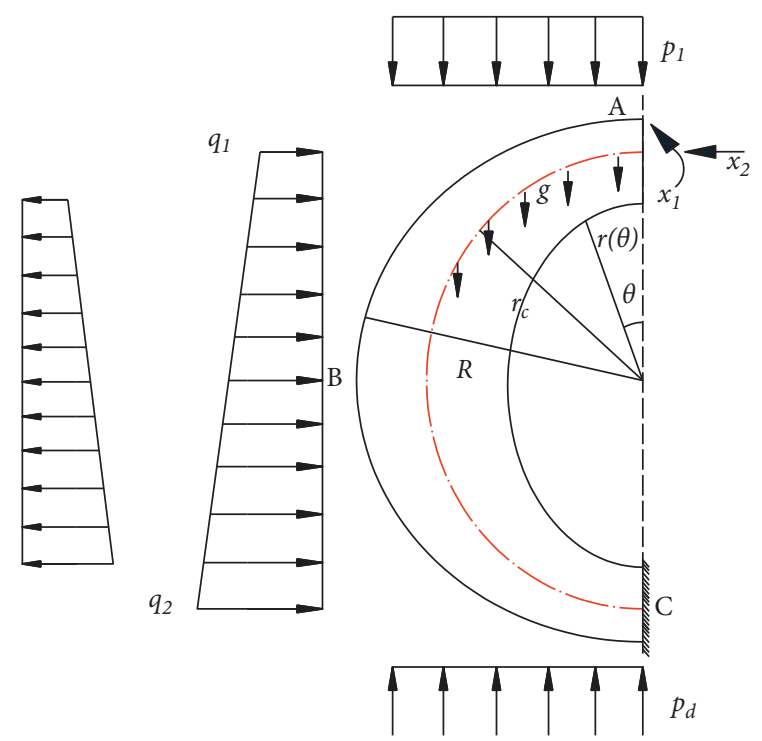

(b)

FiguRE 2: Load model and basic structure of outer circle and inner ellipse shield tunnel linings. (a) Load modeling. (b) Basic structure.

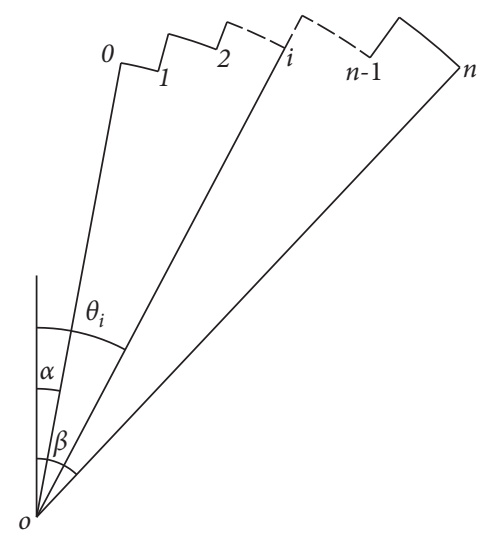

FIGURE 3: Unit step function diagram.

$$
H(\theta)=\left(\theta-\theta_{i}\right)= \begin{cases}0, & \left(\theta<\theta_{i}\right), \\ 1, & \left(\theta>\theta_{i}\right) .\end{cases}
$$

Then, the step function $f(\theta)$ can be described by a linear combination of unit step functions, as shown in the following:

$$
\begin{aligned}
f(\theta) & =f\left(\theta_{0+}\right)+\sum_{i=1}^{n-1}\left[f\left(\theta_{i}\right)\right] \cdot H(\theta) \\
& =f\left(\theta_{0+}\right)+\sum_{i=1}^{n-1}\left[f\left(\theta_{i+}\right)-f\left(\theta_{i-}\right)\right] \cdot H(\theta),
\end{aligned}
$$

where $\left[f\left(\theta_{i}\right)\right]=f\left(\theta_{i+}\right)-f\left(\theta_{i-}\right)$ is the amount of jump in the step function $f\left(\theta_{i}\right)$ at $\theta_{i}$.

The inner contour of the shield tunnel linings was stepped down, as shown in Figure 4.

Its structural stiffness also varies in steps, so it can be described using the step function, that is,

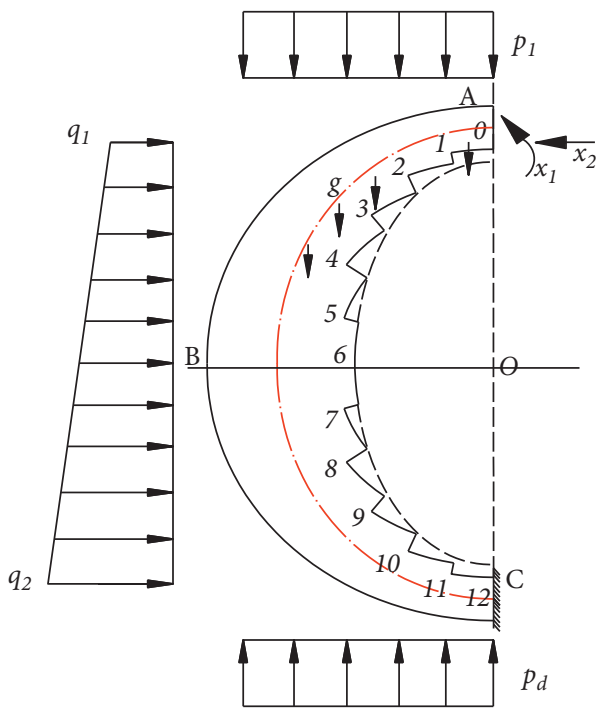

FIgURE 4: Basic structure of inner contour stepping treatment.

$$
\begin{aligned}
E I(\theta) & =E I\left(\theta_{0+}\right)+\sum_{i=1}^{n-1}\left[E I\left(\theta_{i}\right)\right] \cdot H(\theta) \\
& =E I\left(\theta_{0+}\right)+\sum_{i=1}^{n-1}\left[E I\left(\theta_{i+}\right)-E I\left(\theta_{i-}\right)\right] \cdot H(\theta) \\
& =E \frac{b \prime h^{3}\left(\theta_{0+}\right)}{12}+\sum_{i=1}^{n-1}\left[E \frac{b \prime h^{3}\left(\theta_{i+}\right)}{12}-E \frac{b \prime h^{3}\left(\theta_{i-}\right)}{12}\right] \cdot H(\theta) .
\end{aligned}
$$

Since the effect of the axial force on the structural displacement is small, it can be neglected in the calculation, and therefore, equation (2) can be written as 


$$
\begin{aligned}
\int_{s} \frac{M_{P} \bar{M}_{k}}{E I} \mathrm{~d} s & =\int_{\alpha}^{\beta} \frac{M_{P} \bar{M}_{k}}{E I(\theta)} \cdot r_{c} \mathrm{~d} \theta \\
& =\left.\frac{r_{c}}{E I(\theta)} F\left(M_{P}\right) F\left(\bar{M}_{k}\right)\right|_{\alpha} ^{\beta}-\int_{\alpha}^{\beta} M_{P} \bar{M}_{k} \cdot r_{c} d \frac{1}{E I(\theta)}
\end{aligned}
$$

Assuming that the inverse of the variable intercept and variable moment of inertia in the product function still varies linearly in steps and the generalized derivative of the unit step function is denoted by $\delta\left(\theta-\theta_{i}\right)$, then

$$
d \frac{1}{E I(\theta)}=\sum_{i=1}^{n-1}\left[\frac{1}{E I\left(\theta_{i+}\right)}-\frac{1}{E I\left(\theta_{i-}\right)}\right] \cdot \delta(\theta)
$$

Substituting the above equation back into equation (6),

$$
\int_{s} \frac{M_{P} \bar{M}_{k}}{E I} \mathrm{~d} s=\left[\frac{1}{E I_{0}}+\sum_{i=1}^{n-1}\left(\frac{1}{E I_{i+1}}-\frac{1}{E I_{i}}\right)\right] r_{c} \int_{\alpha}^{\beta} M_{P} \bar{M}_{k} \mathrm{~d} \theta-r_{c} \sum_{i=1}^{n-1}\left(\frac{1}{E I\left(\theta_{i+}\right)}-\frac{1}{E I\left(\theta_{i-}\right)}\right) H(\theta) \int_{\alpha}^{\theta_{i}} M_{P} \bar{M}_{k} \mathrm{~d} \theta
$$

which makes

$$
\left\{\begin{array}{l}
\left(\frac{1}{E I_{i+1}}-\frac{1}{E I_{i}}\right) \int_{s i} M_{P} \bar{M}_{k} \mathrm{~d} s=\frac{1}{E}\left(\frac{1}{I_{i+1}}-\frac{1}{I_{i}}\right) \int_{s i} M_{P} \bar{M}_{k} \mathrm{~d} s \\
{\left[\frac{1}{E I_{0}}+\sum_{i=1}^{n-1}\left(\frac{1}{E I_{i+1}}-\frac{1}{E I_{i}}\right)\right] \int_{s} M_{P} \bar{M}_{k} \mathrm{~d} s=\frac{1}{E I_{\max }} \int_{s} M_{P} \bar{M}_{k} \mathrm{~d} s}
\end{array}\right.
$$

The equation of the flexibility coefficient and the free term of the outer circle and inner ellipse are obtained as follows:

$$
\Delta_{k P}=\frac{1}{E I_{\max }} \int_{s} M_{P} \bar{M}_{k} \mathrm{~d} s-\frac{1}{E} \sum_{i=1}^{n-1}\left(\frac{1}{I_{i+1}}-\frac{1}{I_{i}}\right) \int_{s i} M_{P} \bar{M}_{k} \mathrm{~d} s .
$$

The application of equation (10) to calculate the flexibility coefficients and the free terms are approximated as compared with equation (2), and its accuracy improves with an increase in the number of steps.

2.2.2. The Equation of Internal Force of the Outer Circular and Inner Elliptical Shield Tunnel Linings. The expression of the internal force of the basic structure under the action of an unknown unit force is

$$
\begin{aligned}
& \bar{M}_{1}=1, \\
& \bar{N}_{1}=0, \\
& \bar{Q}_{1}=0, \\
& \bar{M}_{2}=r_{c}(1-\cos \theta), \\
& \bar{N}_{2}=\cos \theta, \\
& \bar{Q}_{2}=-\sin \theta .
\end{aligned}
$$
is

The expression of the internal force under external load

$M_{p}\left\{\begin{array}{l}M_{p 1}=\frac{r_{c}^{2}}{2}\left[-p_{1} \cdot \sin ^{2} \theta-q_{1} \cdot(1-\cos \theta)^{2}-\frac{\left(q_{2}-q_{1}\right)}{6} \cdot(1-\cos \theta)^{3}-2 g \cdot(\cos \theta+\theta \sin \theta-1)\right] \quad\left(0 \leq \theta<\frac{\pi}{2}\right), \\ M_{p 2}=\frac{r_{c}^{2}}{2}\left[-p_{1} \cdot \sin ^{2} \theta-p_{g} \cdot(1-\sin \theta)^{2}-q_{1} \cdot(1-\cos \theta)^{2}-\frac{\left(q_{2}-q_{1}\right)}{6} \cdot(1-\cos \theta)^{3}-2 g \cdot(\cos \theta+\theta \sin \theta-1)\right] \quad\left(\frac{\pi}{2} \leq \theta \leq \pi\right),\end{array}\right.$

$N_{p}\left\{\begin{array}{l}N_{p 1}=r_{c}\left[p_{1} \cdot \sin ^{2} \theta-q_{1} \cdot(1-\cos \theta) \cdot \cos \theta-\frac{\left(q_{2}-q_{1}\right)}{4} \cdot(1-\cos \theta)^{2} \cdot \cos \theta+g \cdot \theta \sin \theta\right] \quad\left(0 \leq \theta<\frac{\pi}{2}\right), \\ N_{p 2}=r_{c}\left[p_{1} \cdot \sin ^{2} \theta-p_{g} \cdot(1-\sin \theta) \cdot \sin \theta-q_{1} \cdot(1-\cos \theta) \cdot \cos \theta-\frac{\left(q_{2}-q_{1}\right)}{4} \cdot(1-\cos \theta)^{2} \cdot \cos \theta+g \cdot \theta \sin \theta\right] \quad\left(\frac{\pi}{2} \leq \theta \leq \pi\right),\end{array}\right.$

$Q_{p}\left\{\begin{array}{l}Q_{p 1}=r_{c}\left[p_{1} \cdot \sin \theta \cdot \cos \theta+q_{1} \cdot(1-\cos \theta) \cdot \sin \theta+\frac{q_{2}-q_{1}}{4} \cdot(1-\cos \theta)^{2} \cdot \sin \theta+g \cdot \theta \cos \theta\right] \quad\left(0 \leq \theta<\frac{\pi}{2}\right), \\ Q_{p 2}=r_{c}\left[p_{1} \cdot \sin \theta \cdot \cos \theta-p_{g} \cdot(1-\sin \theta) \cdot \cos \theta+q_{1} \cdot(1-\cos \theta) \cdot \sin \theta+\frac{q_{2}-q_{1}}{4} \cdot(1-\cos \theta)^{2} \cdot \sin \theta+g \cdot \theta \cos \theta\right] \quad\left(\frac{\pi}{2} \leq \theta \leq \pi\right) .\end{array}\right.$ 
Substituting equations (11) to (15) into equation (10), the force method calculation coefficients of the outer circular inner elliptical shield tunnel linings can be found and brought into the force method equation to obtain the basic unknown force of the structure, and finally, the internal force equation of the outer circular inner elliptical shield tunnel linings is found, that is,

$$
\begin{aligned}
& M=\left\{\begin{array}{l}
\left(\frac{\delta_{12} \Delta_{2 P}-\delta_{22} \Delta_{1 P}}{\delta_{11} \delta_{22}-\delta_{12} \delta_{21}}\right)+r_{c}(1-\cos \theta) \frac{\delta_{12} \Delta_{1 P}-\delta_{11} \Delta_{2 P}}{\delta_{11} \delta_{22}-\delta_{12} \delta_{21}}+M_{p 1} \quad\left(0 \leq \theta<\frac{\pi}{2}\right), \\
\left(\frac{\delta_{12} \Delta_{2 P}-\delta_{22} \Delta_{1 P}}{\delta_{11} \delta_{22}-\delta_{12} \delta_{21}}\right)+r_{c}(1-\cos \theta) \frac{\delta_{12} \Delta_{1 P}-\delta_{11} \Delta_{2 P}}{\delta_{11} \delta_{22}-\delta_{12} \delta_{21}}+M_{p 2} \quad\left(\frac{\pi}{2} \leq \theta \leq \pi\right),
\end{array}\right. \\
& N= \begin{cases}\left(\frac{\delta_{12} \Delta_{1 P}-\delta_{11} \Delta_{2 P}}{\delta_{11} \delta_{22}-\delta_{12} \delta_{21}}\right) \cos \theta+N_{p 1} \quad\left(0 \leq \theta<\frac{\pi}{2}\right), \\
\left(\frac{\delta_{12} \Delta_{1 P}-\delta_{11} \Delta_{2 P}}{\delta_{11} \delta_{22}-\delta_{12} \delta_{21}}\right) \cos \theta+N_{p 2} & \left(\frac{\pi}{2} \leq \theta \leq \pi\right), \\
-\left(\frac{\delta_{12} \Delta_{1 P}-\delta_{11} \Delta_{2 P}}{\delta_{11} \delta_{22}-\delta_{12} \delta_{21}}\right) \sin \theta+Q_{p 1} & \left(0 \leq \theta<\frac{\pi}{2}\right), \\
-\left(\frac{\delta_{12} \Delta_{1 P}-\delta_{11} \Delta_{2 P}}{\delta_{11} \delta_{22}-\delta_{12} \delta_{21}}\right) \sin \theta+Q_{p 2} & \left(\frac{\pi}{2} \leq \theta \leq \pi\right) .\end{cases}
\end{aligned}
$$

\section{Example Analysis}

3.1. Engineering Geological Conditions. Taking a project of the Xi'an subway as an example [33], the project interval is located from Zhangjiabao Square to the cross of Windy City Road 5 in Xi' an, and the Earth pressure balance shield machine is used in the project. The minimum curvature radius of the shield machine is $150 \mathrm{~m}$, the maximum slope is $40 \%$, and the total length of the shield machine is $8.68 \mathrm{~m}$. Shield diameter is $6.14 \mathrm{~m}$, shield tail clearance is $30 \mathrm{~mm}$, propulsion lever stroke is $2.5 \mathrm{~m}$, and cutter head opening rate is $62 \%$. The internal force distribution characteristics of the equal-stiffness shield tunnel linings design and the external circular internal elliptical shield tunnel linings design are compared, and the stability evaluation is shown in combination with relevant safety requirements. The minimum and maximum burial depths of the tunnel overburden are $8.5 \mathrm{~m}$ and $11.6 \mathrm{~m}$, respectively. The minimum distance of the groundwater level from the ground is $4.8 \mathrm{~m}$, and the lateral pressure coefficient is $\lambda=0.45$, and the soil parameters are shown in Tables 1 and 2 .

Ground overload $q_{0}=30 \mathrm{kN} / \mathrm{m}^{2}$, vertical load $P_{1}=229.05 \mathrm{kN} / \mathrm{m}$, horizontal load $q_{1}=103.0725 \mathrm{kN} / \mathrm{m}$, horizontal load $q_{2}=154.44 \mathrm{kN} / \mathrm{m}$, bottom reaction load $P_{d}=P_{1}+P_{g}=252.612 \mathrm{kN} / \mathrm{m}$, and reinforced concrete heaviness is $25 \mathrm{kN} / \mathrm{m}^{3}$.

3.2. Calculation of Internal Forces. The outer diameter of the isostatic shield tunnel linings used in the project was $3 \mathrm{~m}$, and the thickness was $0.3 \mathrm{~m}$. The above parameters are introduced into the usual design method [11] to solve for the internal forces of the isostatic shield tunnel linings, as shown in Figure 5. From the axial variation theory [34], it is known that when the lateral pressure coefficient is less than 1, the elliptical structure has the best adaptability, so in this case, the elliptical "outer circle inner elliptical" structure is chosen, as shown in Figure 6(a), where the thin black solid line is the circular outer contour of the shield tunnel linings, and the thick blue solid line is the circular inner contour of the equal stiffness shield tunnel linings. The black thick solid line is the inner contour of the outer circle and the inner ellipse, and the red shading indicates the area difference between the two structures. After many calculations, the outer diameter of the "outer circle and inner oval" shield tunnel linings is taken as $R=3 \mathrm{~m}$. The inner profile long and short axes are $\mathrm{a}=2.78 \mathrm{~m}, b=2.72 \mathrm{~m}$, and width $b_{l}=1 \mathrm{~m}$. The rest of the conditions are consistent with the iso-rigid shield tunnel linings. At this point, the radius of the inner contour of the outer and inner elliptical shield tunnel linings is given by

$$
r(\theta)=\sqrt{\frac{a^{2} b^{2}}{b^{2} \cos ^{2} \theta+a^{2} \sin ^{2} \theta}} .
$$

The basic structure of the outer circular inner elliptic shield tunnel linings and its stepping is shown in Figure 6(b). As shown in equation (10), a more detailed stepping division will give more accurate results, although the calculation process will be more complicated. To illustrate the above calculation method, here the internal contour of the structure is divided into 12 sections and 10 steps. 
TABLE 1: Soil parameters.

\begin{tabular}{|c|c|c|c|c|}
\hline Soil layer number & Soil layer & Severe $\left(\mathrm{kN} / \mathrm{m}^{3}\right)$ & Thickness (m) & Position \\
\hline $1-2$ & Vegetative fill & 15.9 & 1.7 & \\
\hline $2-1-1$ & Loess-like soil & 16.4 & 5.3 & Tunnel overlay \\
\hline $2-1-2$ & Loess & 18.5 & $\begin{array}{l}4.6 \\
2.5\end{array}$ & \multirow{2}{*}{ The stratum in which the tunnel is located } \\
\hline $2-2$ & Ancient soil & 19.4 & 3.5 & \\
\hline
\end{tabular}

TABLE 2: Soil physical index.

\begin{tabular}{|c|c|c|c|c|c|c|c|c|}
\hline Soil layer & $\begin{array}{l}\text { Natural moisture } \\
\text { content }(\%)\end{array}$ & $\begin{array}{l}\text { Mass density } \\
\left(\mathrm{g} / \mathrm{cm}^{3}\right)\end{array}$ & $\begin{array}{l}\text { Dry density } \\
\left(\mathrm{g} / \mathrm{cm}^{3}\right)\end{array}$ & $\begin{array}{l}\text { Saturation } \\
\text { degree }(\%)\end{array}$ & $\begin{array}{c}\text { Void } \\
\text { ratio (\%) }\end{array}$ & $\begin{array}{c}\text { Internal friction } \\
\text { angle }\left({ }^{\circ}\right)\end{array}$ & $\begin{array}{l}\text { Cohesion } \\
(\mathrm{kPa})\end{array}$ & $\begin{array}{l}\text { Poisson's } \\
\text { ratio }\end{array}$ \\
\hline $\begin{array}{l}\text { Vegetative } \\
\text { fill }\end{array}$ & 22.1 & 1.73 & 1.42 & 62.8 & 49 & - & - & 0.32 \\
\hline $\begin{array}{l}\text { Loess-like } \\
\text { soil }\end{array}$ & 25.7 & 1.92 & 1.53 & 89.3 & 44 & 19.7 & 37 & 0.32 \\
\hline Loess & 21.9 & 2.04 & 1.68 & 94 & 38 & 21 & 43 & 0.28 \\
\hline Ancient soil & 24.2 & 2.01 & 1.62 & 94.4 & 40 & 18.3 & 38 & 0.32 \\
\hline
\end{tabular}

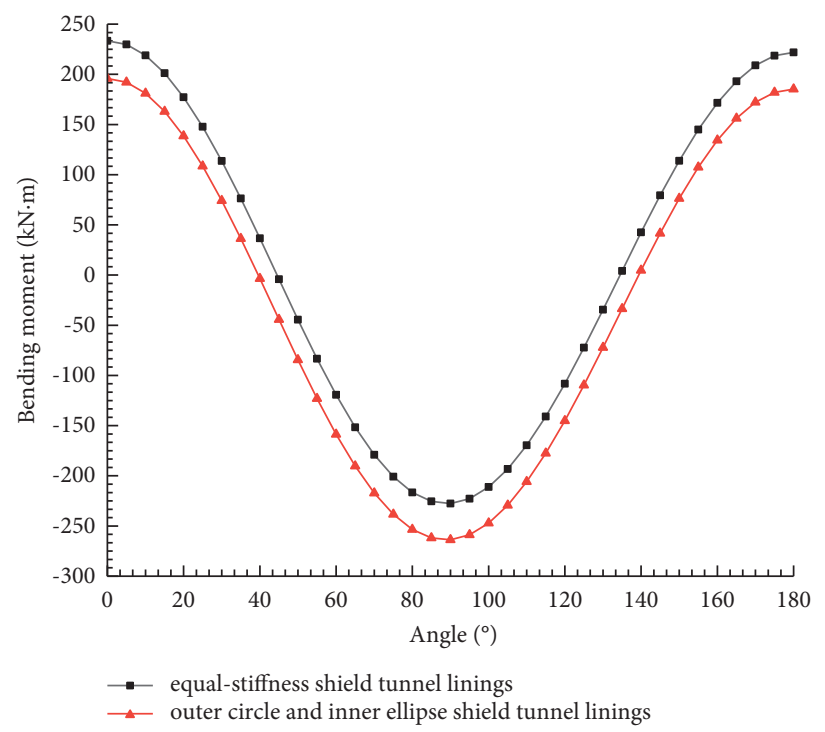

(a)

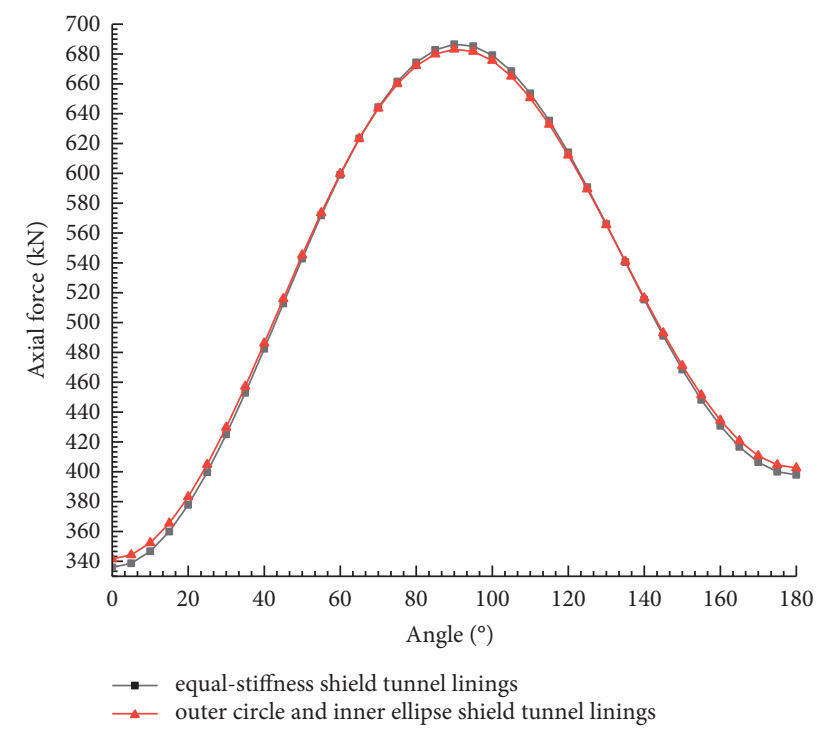

(b)

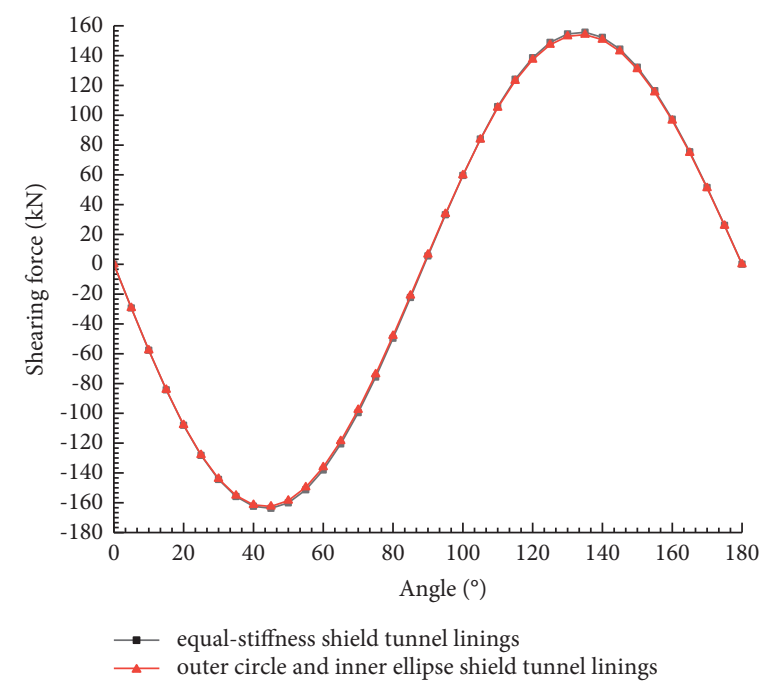

(c)

FIGURE 5: Comparison of internal force distribution between iso-stiffness shield tunnel linings and outer circle and inner ellipse shield tunnel linings. (a) Bending moment. (b) Axial force. (c) Shear force. 

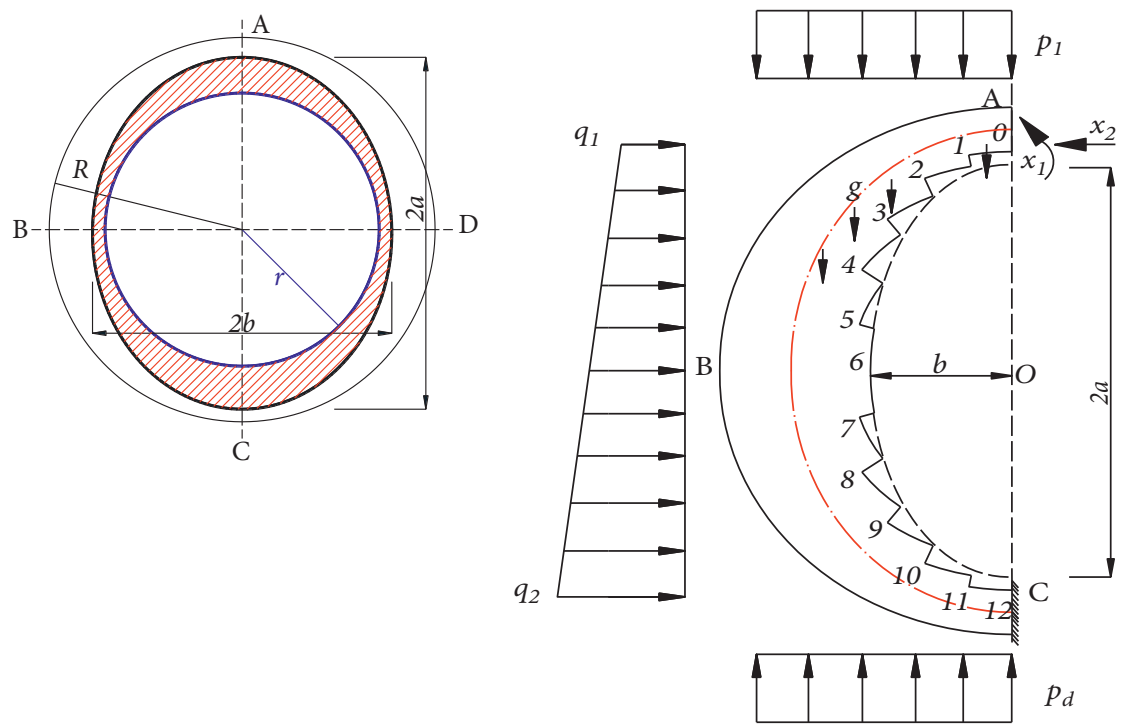

(a)

(b)

FIGURE 6: Outer circle and inner ellipse shield tunnel linings and stepwise basic structure. (a) Outer round inner oval shield tunnel lining. (b) Outer round inner oval shield tunnel lining with stepped basic structure.

The geometric data required for the calculation and the calculated parameters are shown in Table 3 (symmetric structure, only $0^{\circ}$ to $90^{\circ}$ data are shown).
Bringing the data in Table 2 and the internal force equation into equation (10), we find that the coefficient $\delta_{11}$ in the force law equation is

$$
\begin{aligned}
\delta_{11}= & \frac{r_{c}}{E I_{6}} \int_{0}^{\pi / 2} M_{p} \bar{M}_{1} \mathrm{~d} \theta-\frac{r_{c}}{E}\left[\left(\frac{1}{I_{2}-I_{1}}\right) \int_{0}^{\pi / 12} M_{p} \bar{M}_{1} \mathrm{~d} \theta+\left(\frac{1}{I_{3}-I_{2}}\right) \int_{0}^{\pi / 6} M_{p} \bar{M}_{1} \mathrm{~d} \theta+\cdots+\left(\frac{1}{I_{6}-I_{5}}\right) \int_{0}^{5 \pi / 12} M_{p} \bar{M}_{1} \mathrm{~d} \theta\right] \\
& +\frac{r_{c}}{E I_{6}} \int_{\pi / 2}^{\pi} M_{p} \bar{M}_{1} \mathrm{~d} \theta-\frac{r_{c}}{E}\left[\left(\frac{1}{I_{6}-I_{7}}\right) \int_{7 \pi / 12}^{\pi} M_{p} \bar{M}_{1} \mathrm{~d} \theta+\left(\frac{1}{I_{7}-I_{8}}\right) \int_{2 \pi / 3}^{\pi} M_{p} \bar{M}_{1} \mathrm{~d} \theta+\cdots+\left(\frac{1}{I_{10}-I_{11}}\right) \int_{11 \pi / 12}^{\pi} M_{p} \bar{M}_{1} \mathrm{~d} \theta\right] \\
= & 2427.258186 \frac{r_{c}}{E} .
\end{aligned}
$$

Similarly, it is known that the other calculation coefficients are

$$
\begin{aligned}
& \delta_{22}=3983.562236 \frac{r_{c}^{3}}{E}, \\
& \delta_{12}=\delta_{21}=2427.258187 \frac{r_{c}^{2}}{E}, \\
& \Delta_{1 P}=-336439.6240 \frac{r_{c}^{3}}{E}, \\
& \Delta_{2 P}=-520551.5199 \frac{r_{c}^{4}}{E} .
\end{aligned}
$$

Substituting the above parameters into equations (16) (18), the internal force distribution of the outer circular inner elliptical shield tunnel linings is obtained; the calculated results are compared with those of the literature [29], as shown in Figure 5.
From Figure 5, it can be seen that, under the same load, the change trend of the internal force distribution of the equal-stiffness shield tunnel linings and the outer circular inner elliptical shield tunnel linings are basically similar.

From Figure 5(a), it can be seen that the positive and negative maximum bending moments of the two types of shield tunnel linings occur at the top $\left(\theta=0^{\circ}\right)$ and waist $\left(\theta=90^{\circ}\right)$, and the bending moments at the top are larger than those at the bottom $\left(\theta=180^{\circ}\right)$. The positive and negative maximum bending moments of the outer circular inner elliptical shield tunnel linings are $195.8775 \mathrm{kN} \cdot \mathrm{m}$ and $-263.6933 \mathrm{kN} \cdot \mathrm{m}$, respectively, and the positive and negative maximum bending moments of the equal-stiffness shield tunnel linings are $233.3539 \mathrm{kN} \cdot \mathrm{m}$ and $-227.5817 \mathrm{kN} \cdot \mathrm{m}$, respectively, that is, the bending moment hazard section of the equal-stiffness shield tunnel linings is at the top, while the outer circular inner elliptical shield tunnel linings shift the bending moment hazard section to the waist. 
TABLE 3: Geometric data and calculated parameters of the stepped structure.

\begin{tabular}{cccccc}
\hline$i$ & $\theta_{i}$ & $r_{c}\left(\theta_{i}\right)(\mathrm{m})$ & $h_{i}(\mathrm{~m})$ & $I_{i}\left(\mathrm{~m}^{4}\right)$ & $1 / I_{i}$ \\
\hline 0 & 0 & 2.89 & 0.22 & 0.000887 & 0.000938 \\
1 & 15 & 2.8879 & 0.2241 & 0.001087 & 106.9722 \\
2 & 30 & 2.8823 & 0.2354 & 0.001310 & 920.2788 \\
3 & 45 & 2.8748 & 0.2505 & 0.001557 & 763.4938 \\
4 & 60 & 2.8673 & 0.2654 & 0.001754 & 542.1716 \\
5 & 75 & 2.8619 & 0.2761 & 0.001829 & 540.1309 \\
6 & 90 & 2.86 & 0.28 & & 546.6472 \\
\hline
\end{tabular}

From Figure 5(b), it can be seen that the maximum axial force of both types of shield tunnel linings occurs at the waist, and the axial force at the bottom is larger than that at the top. In addition, at the waist, the maximum axial force of the outer circular inner ellipse is smaller than that of the equal-stiffness shield tunnel linings. On the contrary, at the top and bottom, the axial force of the outer circular inner ellipse is the largest. From Figure 5(c), it can be seen that the maximum shear force of the outer circle inner ellipse is smaller than that of the equal-stiffness shield tunnel linings. In conclusion, in the internal force distribution level of the structural design, the equal-stiffness shield tunnel linings must consider both the influence of the maximum bending moment at the top and the influence of the maximum axial force at the waist, while the outer circular inner elliptical shield tunnel linings transfer the maximum bending moment to the waist and reduce the bending moment values at the top and bottom, which simplifies the design elements by focusing on whether the structural stiffness at the waist meets the safety conditions during the verification.

3.3. Stability Evaluation. In accordance with the "Code for Design of Railway Tunnel”(TB1003-2016) relevant requirements, after obtaining the distribution of internal forces in the cross section, it is necessary to select the maximum positive and negative bending moment and the axial force at the location; for safety factor calibration, the specific criteria are calculated according to the following formula:

$$
K N \leq R_{w} b^{\prime} x+R_{g}\left(A_{g}-A_{g}^{\prime}\right) .
$$

The neutral axis position is determined by the following formula:

$$
R_{g}\left(A_{g} e \mp A_{g}^{\prime} e^{\prime}\right)=R_{w} b^{\prime} x\left(e-h_{0}+\frac{x}{2}\right) .
$$

For concrete shield tunnel linings, it is also necessary to check the shear strength at its maximum shear position, and the specific criteria are calculated according to the following formula:

$$
K Q \leq 0.3 R_{a} b^{\prime} h_{0},
$$

where $K$ is the safety check factor, $N$ is the cross-sectional axial force, $R_{a}$ is the compressive ultimate strength of the concrete, $R_{w}$ is the bending compressive ultimate strength of concrete, $b^{\prime}$ is the cross-sectional width, $x$ is the height of the concrete pressure zone, $R_{g}$ is calculated tensile or compressive strength of reinforcing steel, $A_{g}$ and $A_{g}^{\prime}$ are the cross-sectional area of reinforcement in tension and compression zones, $h_{0}$ is the effective height of the cross section, and $e$ and $e^{\prime}$ are the distance from the point of action of the tensile and compressive reinforcement to the axial force.

Combined with the calculation results obtained in the previous section, the dangerous sections of the two types of shield tunnel linings and their internal forces are listed in Table 4.

The two types of shield tunnel linings in this example are made of C50 concrete with material parameters $R_{a}=36.5 \mathrm{MPa}$ and $R_{w}=45.6 \mathrm{MPa}$; the reinforcement grade was HPB400, where the tensile and compressive reinforcement and their parameters were C18 $\left(A_{g}=2036 \mathrm{~mm}^{2}\right)$, C16 $\left(A_{g}^{\prime}=1206 \mathrm{~mm}^{2}\right)$, and $R_{g}=400 \mathrm{MPa}$. Substituting Table 3 parameters and material parameters into equations (22) (24), the safety factors of the two types of shield tunnel linings are obtained, as shown in Table 5.

According to the specification, when the reinforcement in the lining reaches the calculated strength or the concrete reaches the compressive or shear ultimate strength under the main load, the strength safety coefficient $K$ of the structure is not less than 2.0. As can be seen from Table 4, the safety coefficients of both types of shield tunnel linings at the maximum negative bending moment are smaller than those at the maximum positive bending moment, while the safety coefficients at the maximum shear force are much larger than the safety requirements. Compared with the equalstiffness shield tunnel linings, the safety coefficient of the outer round inner elliptical shield tunnel linings used in this case is slightly lower, but still meets the safety requirements, which not only can give full play to the concrete material characteristics but also lower the overall project cost. In terms of the internal space area, the usable area of one ring of equal stiffness shield tunnel linings is $22.9 \mathrm{~m}^{2}$, while the usable area of one ring of outer circle inner ellipse shield tunnel linings is $23.76 \mathrm{~m}^{2}$, which is obviously larger than that of equal-stiffness shield tunnel linings so that more necessary equipment can be accommodated without expanding the outer diameter.

Although the shield machine jack thrust is a temporary construction load, it is the largest among the construction loads; therefore, it is necessary to verify the stability of the shield tunnel linings in the axial direction under the shield machine jack thrust, and the specific verification is based on the following type: 
TABle 4: Dangerous sections of the structure and their internal forces.

\begin{tabular}{|c|c|c|c|c|}
\hline Structure type & $\theta\left(^{\circ}\right)$ & $M(\mathrm{kN} \cdot \mathrm{m})$ & $N(\mathrm{kN})$ & $Q(\mathrm{kN})$ \\
\hline \multirow{3}{*}{ Iso-stiffness shield tunnel linings } & 0 & 233.3539 & 335.9433 & 0 \\
\hline & 45 & 4.1068 & 540.5678 & -163.7784 \\
\hline & 90 & -227.5817 & 686.4683 & 5.5873 \\
\hline \multirow{3}{*}{ Outer round inner oval shield tunnel linings } & 0 & 195.8775 & 341.6527 & 0 \\
\hline & 45 & -3.5322 & 515.9133 & -162.5058 \\
\hline & 90 & -263.6933 & 683.1610 & 6.5911 \\
\hline
\end{tabular}

TABLE 5: Safety factor $K$.

\begin{tabular}{lccc}
\hline Structure type & \multicolumn{2}{c}{ Calibration position } \\
& Max. positive bending moment & Max. shear force & Max. axial force \\
\hline Iso-stiffness shield tunnel linings & 3.07 & 18.05 & 2.45 \\
Outer round inner oval shield tunnel linings & 2.79 & 14.86 & 2.21 \\
\hline
\end{tabular}

$$
\sigma_{\max }=P\left(\frac{1}{A_{0}}+e_{1} \frac{h / 2}{I^{\prime}}\right) \leq \sigma_{w}
$$

where $P$ is the single jack thrust, $A_{0}$ is the pad top base contact area, $e_{1}$ is the eccentricity between the center of gravity of the jack and the direction of the radius of the shape of the shield tunnel linings, $I^{\prime}$ is the sectional moment of inertia over the width of the pad top base, and $\sigma_{w}$ is the permissible concrete stress; the specific parameters are listed in Table 6.

Substituting the data from Table 5 into (25), the maximum compressive stresses in the vault and waist of the shield tunnel linings under the jack thrust of the shield machine are $10.847 \mathrm{MPa}$ and $8.131 \mathrm{MPa}$, respectively, which are less than the allowable stress of $18.2 \mathrm{MPa}$ and meet the safety requirements.

\section{Numerical Simulation}

To verify the correctness of the theoretical analysis, ABAQUS, a finite element analysis software, was used to numerically simulate the analysis of the outer circular inner elliptical shield tunnel linings. The geometric model and loading conditions were kept consistent with the previous section, and solid units were used to simulate the shield tunnel linings, and truss units were used to simulate the steel reinforcement; the specific material parameters are listed in Table 7.

The elastic model was selected for both the concrete and reinforcement principal structure models, and the data in Table 7 were entered into the calculation program. The general static analysis was used, and the surface traction was applied to the finite element model according to the loading conditions in the previous section. The finite element model of the shield tunnel linings and the shield tunnel lining reinforcement was established according to the above conditions, as shown in Figure 7.

In the mesh division, a hexahedral secondary complete cell (C3D20) is selected to divide the concrete, which has the advantage of being an accurate calculation and not producing shear self-locking. The reinforcement is divided by 2 -node linear rod cell (T3D2), and the interaction between the two is defined as embedded contact and ignoring relative sliding. In order to ensure the efficiency and accuracy in numerical analysis, trial simulation tests were carried out with $10 \mathrm{~mm}$ being selected as the mesh size in this study.

Figure 8 shows the calculation results of the shield tunnel linings in the form of average Mises stress, where it can be seen that the maximum stress occurs at the inner side of the arch waist of the shield tunnel linings. The results of the internal forces (bending moment, shear force, and axial force) at several key points are output, and the finite element calculation results are compared and analyzed with the theoretical calculation results in this study, and the results are shown in Figure 9 and Table 8.

The maximum axial force calculated by ABAQUS occurs at the arch waist, and the axial force at the arch bottom is larger than that at the arch top, where the maximum axial force value calculated by ABAQUS is slightly larger than the theoretical calculation, and the maximum difference between the absolute values of axial force is $4.941 \mathrm{kN}$; in terms of shear force, the basic change pattern of the results obtained by the two methods is the same. The maximum shear force calculated by ABAQUS occurs at the upper arch shoulder $\left(45^{\circ}\right)$. At the top and bottom of the arch, the result of ABAQUS calculation is not zero. At the upper and lower arch shoulder and arch waist, the theoretical calculation result is greater than the result of $A B A Q U S$ calculation, and the maximum difference between the two absolute values of shear force is $5.906 \mathrm{kN}$. From the above comparative analysis, it can be seen that the theoretical calculation results of the study and the internal force distribution law of the shield tunnel lining structure obtained by ABAQUS finite element analysis are basically consistent, thus verifying the theoretical model of the study. This verifies the correctness of the theoretical model used in this study. 
TABLE 6: Safety verification parameters table.

\begin{tabular}{lcccccr}
\hline$P(\mathrm{kN})$ & \multicolumn{2}{c}{$A_{0}\left(\mathrm{~mm}^{2}\right)$} & $e_{1}(\mathrm{~mm})$ & $\sigma_{w}(\mathrm{MPa})$ & \multicolumn{2}{c}{$I^{\prime}\left(\mathrm{mm}^{4}\right)$} \\
& Vaulting & Arched waist & & & Vaulting & Arched waist \\
\hline 1500 & $1.76 \times 10^{5}$ & $2.24 \times 10^{5}$ & 10 & 18.2 & $709.867 \times 10^{6}$ & $1463.467 \times 10^{6}$ \\
\hline
\end{tabular}

TABLE 7: Concrete and reinforcement material parameters.

\begin{tabular}{lccc}
\hline Materials & Poisson's ratio & Modulus of elasticity $(\mathrm{GPa})$ & Density $\left(\mathrm{kg} / \mathrm{m}^{3}\right)$ \\
\hline Concrete $(\mathrm{C} 50)$ & 0.2 & 34.5 & 2600 \\
Reinforcing steel (HPB400) & 0.3 & 200 & - \\
\hline
\end{tabular}

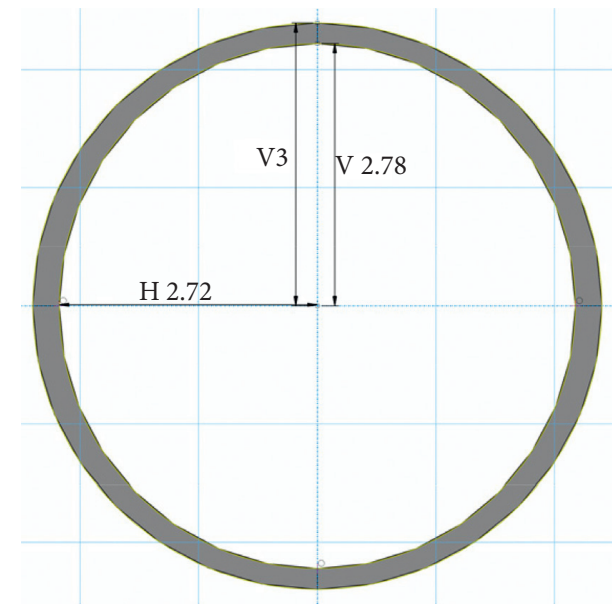

(a)

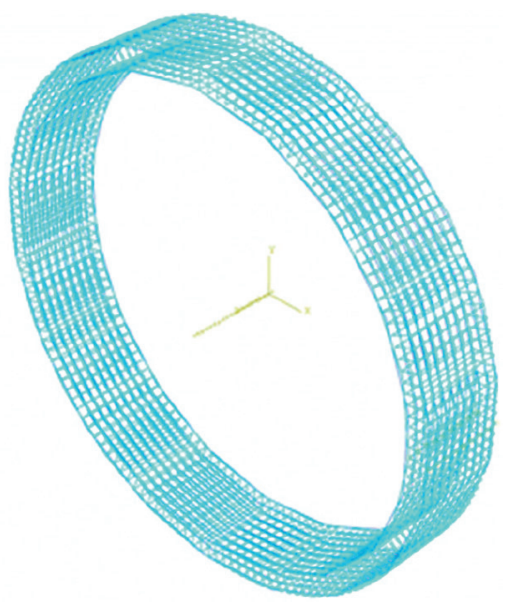

(b)

FIGURE 7: Finite element model of shield tunnel linings and reinforcement. (a) Sketch of cross section of outer circular and inner elliptical shield tunnel linings. (b) Shield tunnel lining reinforcement.

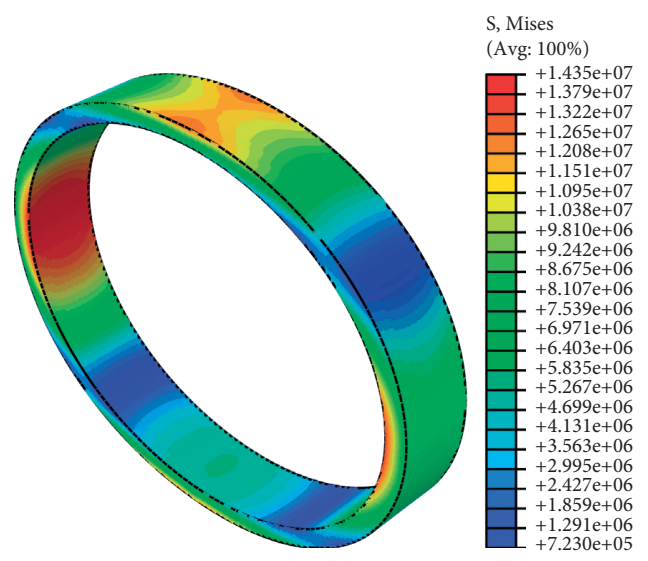

Figure 8: Average Mises stress cloud. 


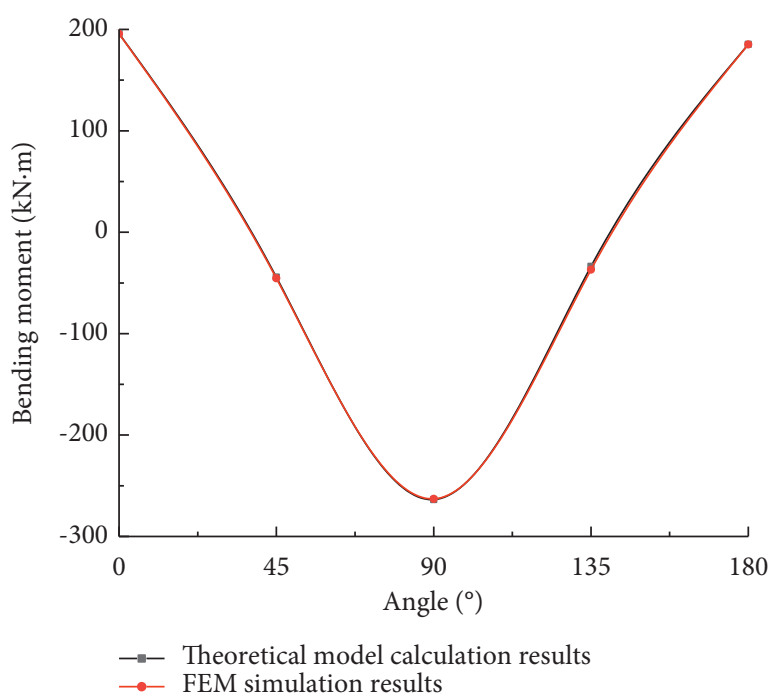

(a)

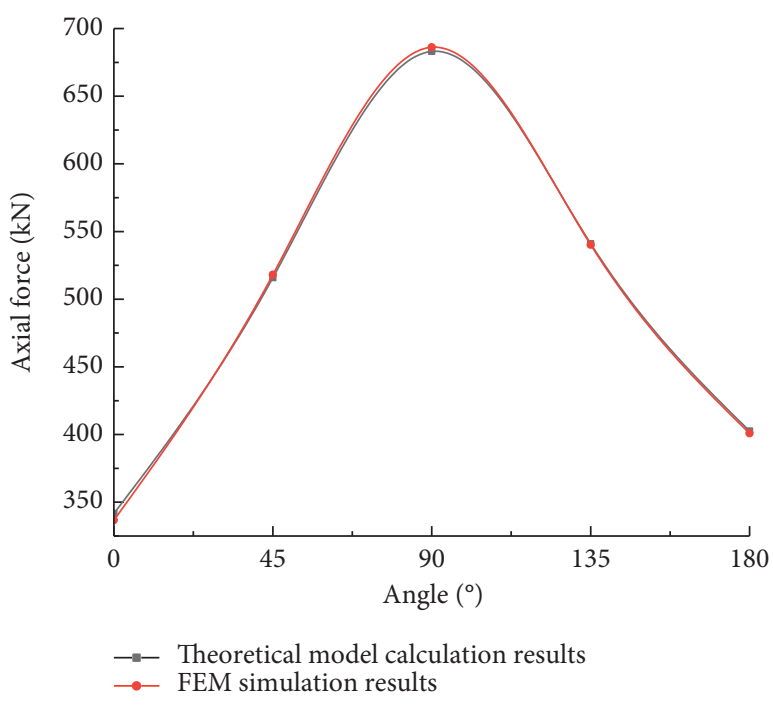

(b)

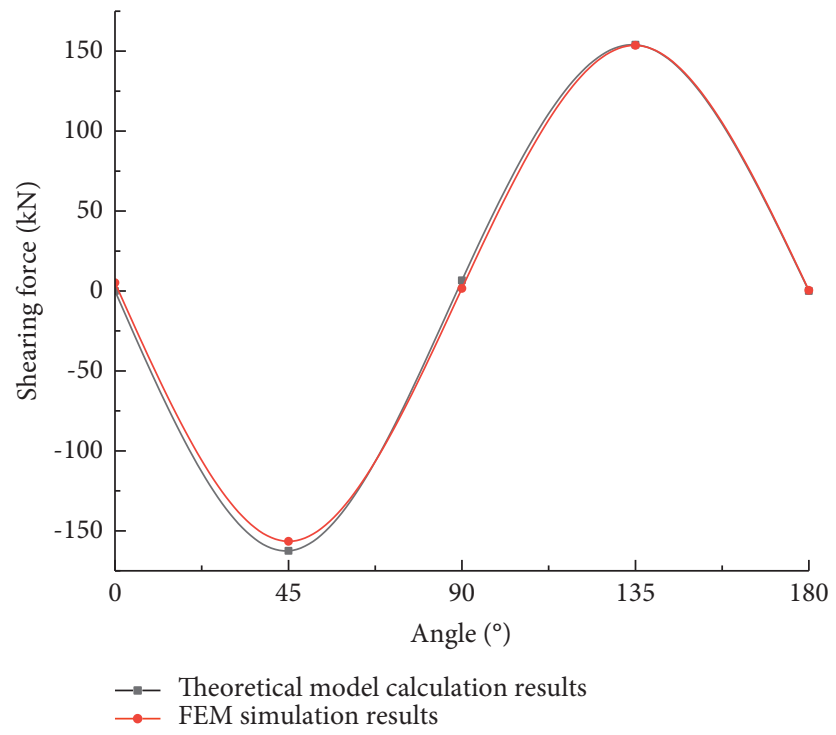

(c)

FIGURE 9: Comparison of numerical simulation and theoretical model analysis results. (a) Bending moment. (b) Axial force. (c) Shear force.

TABLE 8: Comparative analysis of the results of ABAQUS and the theoretical analysis of the paper.

\begin{tabular}{|c|c|c|c|c|c|c|c|c|c|c|}
\hline & \multicolumn{2}{|c|}{$0^{\circ}$} & \multicolumn{2}{|c|}{$45^{\circ}$} & \multicolumn{2}{|c|}{$90^{\circ}$} & \multicolumn{2}{|c|}{$135^{\circ}$} & \multicolumn{2}{|c|}{$180^{\circ}$} \\
\hline & $\begin{array}{c}\text { Theoretical } \\
\text { value }\end{array}$ & $\begin{array}{c}\text { ABAQUS } \\
\text { value }\end{array}$ & $\begin{array}{c}\text { Theoretical } \\
\text { value }\end{array}$ & $\begin{array}{l}\text { ABAQUS } \\
\text { value }\end{array}$ & $\begin{array}{c}\text { Theoretical } \\
\text { value }\end{array}$ & $\begin{array}{l}\text { ABAQUS } \\
\text { value }\end{array}$ & $\begin{array}{c}\text { Theoretical } \\
\text { value }\end{array}$ & $\begin{array}{c}\text { ABAQUS } \\
\text { value }\end{array}$ & $\begin{array}{c}\text { Theoretical } \\
\text { value }\end{array}$ & $\begin{array}{c}\text { ABAQUS } \\
\text { value }\end{array}$ \\
\hline $\begin{array}{l}\text { Bending } \\
\text { moment } \\
(\mathrm{kN} \cdot \mathrm{m})\end{array}$ & 195.878 & 195.544 & -44.243 & -45.446 & -263.69 & -262.953 & -33.608 & -36.882 & 185.274 & 185.168 \\
\hline $\begin{array}{l}\text { Axial } \\
\text { force } \\
(\mathrm{kN})\end{array}$ & 341.653 & 336.712 & 515.913 & 518.135 & 683.161 & 686.228 & 540.915 & 540.202 & 402.558 & 400.921 \\
\hline $\begin{array}{l}\text { Shear } \\
\text { force } \\
(\mathrm{kN})\end{array}$ & 0.000 & 5.160 & -162.51 & -156.600 & 6.591 & 1.626 & 154.037 & 153.562 & 0.000 & 0.392 \\
\hline
\end{tabular}




\section{Conclusions}

(1) In this study, we propose a structure of outer circular inner elliptical shield tunnel linings for shield tunnels in loess. Keeping the outer contour circular, the shape of the inner contour of the structure is appropriately changed according to the loading conditions to ensure that the structural stiffness at the most unfavorable location meets the safety requirements, while reducing the structural stiffness at other locations, so as to fully utilize the material properties and improve the internal space utilization, reduce the cost of construction, and propose a method to calculate the internal force of a variable stiffness structure.

(2) The stiffness step discounting method is used to introduce the unit step function to step the inner contour of the outer circular inner elliptical shield tunnel lining structure, solve the force method calculation coefficients of the outer circular inner elliptical shield tunnel linings, and finally to obtain the internal force equation of the outer circular inner elliptical shield tunnel linings.

(3) In terms of internal force, when the lateral pressure coefficient is less than 1 , the bending moment of the outer circular inner elliptic shield tunnel linings is positive at the top and bottom and negative at the waist. In addition, the positive and negative maximum bending moments are at the top and waist, respectively, and the maximum axial force occurs at the waist. Under the same loading conditions, the maximum bending moment and maximum axial force of the equal-stiffness shield tunnel linings occur at the top and waist, respectively, whereas the outer circular inner elliptical shield tunnel linings reduce the bending moment at the top and bottom and transfer the maximum bending moment to the waist, which simplifies the design elements.

(4) In terms of stability, the safety factor of the outer round inner elliptical shield tunnel linings meets the safety requirements and can fully utilize the concrete material characteristics. In terms of internal space utilization, when the outer diameter is the same for both methods, we found that the outer circle inner elliptical shield tunnel linings method provides more usable area and thus improves the internal space utilization. For the example we investigated, the internal space area of one ring of equal-stiffness shield tunnel linings was $22.9 \mathrm{~m}^{2}$, while that of the outer circle inner ellipse shield tunnel linings was $23.76 \mathrm{~m}^{2}$.

(5) In this study, the concept of outer-circle-inside-elliptic shield tunnel lining is firstly proposed, and the calculation method of internal forces is given. The development of outer circular inner elliptical shield tunnel lining is still in its initial stage, which has important research value and wide application prospect. For related topics, such as prefabrication, installation, and sealing principles, further research by scholars is still needed.

\section{Data Availability}

The data used to support the findings of this study are included within the article.

\section{Conflicts of Interest}

The authors declare that they have no conflicts of interest.

\section{Acknowledgments}

This study was supported by the China Postdoctoral Science Foundation, Surface Grant Project, 2017M623330XB, Shaanxi Provincial Science and Technology Department Fund, Surface Project, 2018JM5126, and Xi'an Geotechnical and Subsurface Engineering Key Laboratory Open Fund Project, XKLGUEKF20-03.

\section{References}

[1] Q. X. Yan, C. Y. Wan, D. J. Zheng, and C. Li, "Conformation design and statistical analysis of large underwater shield tunnel," Railway Standard Design, vol. 60, no. 5, pp. 99104+118, 2016, in Chinese.

[2] W. T. Chen, Z. Y. Jiang, Y. C. Don, and L. Fang, "Discussion on the partition design of large diameter double-shield tbm tunnel shield tunnel linings," Journal of Railway Science and Engineering, vol. 15, no. 1, pp. 170-177, 2018, in Chinese.

[3] W. T. Chen, Z. Q. Fu, and J. X. Ma, "Design research on segment thickness of double shield TBM tunnel with large diameter," Railway Engineering, vol. 57, no. 10, pp. 60-62, 2017, in Chinese.

[4] J. X. Ding, W. X. Feng, and X. L. Du, "Analysis of factors affecting the internal forces and displacement of shield tunnel segment lining," Journal of Shijiazhuang Railway Institute, vol. 2004, no. 3, pp. 75-79, 2004, in Chinese.

[5] G. X. Zhao and C. He, "Analysis of the main influencing factors of shield tunnel linings design," Railway Engineering, vol. 2003, no. 12, pp. 25-29, 2003, in Chinese.

[6] S. H. Huang and Y. W. Wang, "Influence of segment thickness on the force and deformation of large-diameter shield tunnel," Journal of East China Jiaotong University, vol. 37, no. 1, pp. 15-22, 2020, in Chinese.

[7] Z. H. Huang, S. M. Liao, and G. B. Liu, "The optimization of the segment thickness of shield tunnel in Shanghai soft soils," Rock and Soil Mechanics, vol. 2000, no. 4, pp. 326-330, 2000, in Chinese.

[8] Z. H. Huang, S. M. Liao, and G. B. Liu, "The effect of tunnel segment thickness on the behavior of tunnel in use," Architectural Technology, vol. 2000, no. 7, pp. 471-472, 2000.

[9] Y. B. Yang, "Study on segment thickness in tunnel of straddle type monorail shield," Modern Urban Transit, vol. 2019, no. 9, pp. 75-79, 2019, in Chinese.

[10] X. Huang, Y. Zhu, Z. Zhang, Y. Zhu, S. Wang, and Q. Zhuang, "Mechanical behaviour of segmental lining of a sub-rectangular shield tunnel under self-weight," Tunnelling and Underground Space Technology, vol. 74, pp. 131-144, 2018.

[11] X. Liu, Z. Liu, Y. Ye, Y. Bai, and Y. Zhu, "Mechanical behavior of quasi-rectangular segmental tunnel linings: further insights from full-scale ring tests," Tunnelling and Underground Space Technology, vol. 79, pp. 304-318, 2018.

[12] X. Liu, Y. Ye, Z. Liu, and D. Huang, "Mechanical behavior of Quasi-rectangular segmental tunnel linings: first results from 
full-scale ring tests," Tunnelling and Underground Space Technology, vol. 71, pp. 440-453, 2018.

[13] Y. T. Zhu, Y. F. Zhu, Z. X. Zhang, Q. W. Zhuang, and Y. F. Zheng, "Prediction and visualization of crack width for the prototype test on special-shaped shield shield tunnel linings," Journal of Shanghai Jiaotong University, vol. 53, no. 10 , pp. 1259-1268, 2019, in Chinese.

[14] Z. Ji, "Study on optimum design of lining structure of superlarge rectangular section tunnel," China Municipal Engineering, vol. 2018, no. 6, pp. 82-85+106, 2018, in Chinese.

[15] Y. H. Guo, Y. Li, and X. L. Ma, "Determination of the outer profile of variable section lining in highway tunnels," Proceedings of the Chinese Academic Papers on Transportation Civil Engineering" China Civil Engineering Society, vol. 2006, pp. 634-637, 2006, in Chinese.

[16] W. Ding, C. Gong, K. M. Mosalam, and K. Soga, "Development and application of the integrated sealant test apparatus for sealing gaskets in tunnel segmental joints," Tunnelling and Underground Space Technology, vol. 63, pp. 54-68, 2017.

[17] C. J. Gong, W. Q. Ding, and K. Soga, K. M. Mosalam, "Failure mechanism of joint waterproofing in precast segmental tunnel linings," Tunnelling and Underground Space Technology, vol. 84, pp. 334-352, 2019.

[18] C. J. Gong, W. Q. Ding, K. M. Mosalam, and K. Soga, "Comparison of the structural behavior of reinforced concrete and steel fiber reinforced concrete tunnel segmental joints," Tunnelling and Underground Space Technology, vol. 68, pp. 38-57, 2017.

[19] G. Andreotti, G. MicheleCalvi, K. Soga, C. J. Gong, and W. Q. Ding, "Comparison of the structural behavior of reinforced concrete and steel fiber reinforced concrete tunnel segmental joints," Tunnelling and Underground Space Technology, vol. 68, pp. 38-57, 2017.

[20] H. Katebi, A. H. Rezaei, M. Hajialilue-Bonab, and A. Tarifard, "Assessment the influence of ground stratification, tunnel and surface buildings specifications on shield tunnel lining loads (by FEM)," Tunnelling and Underground Space Technology, vol. 49, pp. 67-78, 2015.

[21] H. M. Lyu, S. L. Shen, A. Zhou, and K. L. Chen, "Calculation of pressure on the shallow-buried twin-tunnel in layered strata," Tunnelling and Underground Space Technology, vol. 103, pp. 1-15, 2020.

[22] H. N. Wu, S. L. Shen, S. M. Liao, and Z. Y. Yin, "Longitudinal structural modelling of shield tunnels considering shearing dislocation between segmental rings," Tunnelling and Underground Space Technology, vol. 50, pp. 317-323, 2015.

[23] J. H. Wang, W. J. Zhang, X. Guo, A. Koizumi, and H. Tanaka, "Mechanism for buckling of shield tunnel linings under hydrostatic pressure," Tunnelling and Underground Space Technology, vol. 49, pp. 144-155, 2015.

[24] Y. G. Zheng, G. J Xue, J. B. Chen, and W. Z. Pang, "Development Application and prospect of Technology of specialshaped boring machine in China," Tunnel Construction, vol. 38, no. 6, pp. 1066-1078, 2018, in Chinese.

[25] Y. T. Zhu, Y. F. Zhu, Z. X. Zhang, and X. Huang, "Computational model and mechanical characteristics of linings of special-shaped shield tunnels," Chinese Journal of Geotechnical Engineering, vol. 40, no. 7, pp. 1230-1236, 2018, in Chinese.

[26] Y. . H Zhu, Y. F. Zhu, D. Z. Huang, Z. H. Yang, X. Liu, and S. Liu, "Development and application of key technologies to quasi-rectangular shield tunneling," Tunnel Construction, vol. 37, no. 9, pp. 1055-1062, 2017, in Chinese.
[27] T. L. Sun, "The research status and engineering application of non-circular shield method," Journal of Railway Science and Engineering, vol. 14, no. 9, pp. 1959-1966, 2017, in Chinese.

[28] X. H. Li, "Effects of structural design parameters on mechanical behavior of lining segment for special section shield tunnel," Construction Technology, vol. 46, no. 8, pp. 68-71, 2017, in Chinese.

[29] H. Hu, L. Zhang, and W. G. Qiu, "Comparative analysis of three methods in shield segment design and onsite monitoring analysis," Hydrogeology ang Engineering Geology, vol. 39, no. 6, pp. 72-76, 2012, in Chinese.

[30] K. Y. Ye and H. R. Yu, "Static-indeterminant equi-strength beams," Journal of Lanzhou University, vol. 1983, no. S2, pp. 1-9, 1983, in Chinese.

[31] K. Y. Ye and Y. L. Ding, "The stability and free vibration of non-homogeneous variable thickness continuous beam," Journal of Lanzhou University, vol. 1982, no. 2, pp. 42-74, 1982, in Chinese).

[32] K. Y. Ye, T. J. Tang, and J. .Q. Zhen, "Bending of non-homogeneous variable thickness elastic circular ring under arbitrarily distributed loads," Applied Mathematics and Mechanics, vol. 1981, no. 1, pp. 1-12, 1981, in Chinese.

[33] X. D. Gong, "Shield tunnel linings design of experiment section of shield tunnel of line 2 of Xi 'an subway," Journal of Railway Engineering Society, vol. 2011, pp. 35-38, 2011, in Chinese.

[34] X. F. Yu, "On "the theory of Axlal Variation and basic rules of deformation and fracture of rocks surrounding underground excavations," Uranium Mining And Metallurgy, vol. 1982, no. 1, pp. 8-17+7, 1982. 